\title{
Invasive Meningococcal Disease in Brazil: a literature review
}

\author{
Marcelle Moura Silveira ${ }^{\mathrm{a}, \mathrm{c}^{*}}$, Alan J. A. McBride ${ }^{\mathrm{a}, \mathrm{b}}$, Caroline L. Trotter

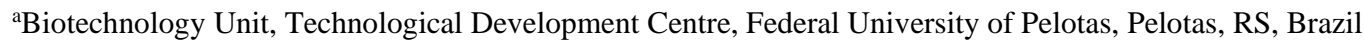 \\ ${ }^{\mathrm{b}}$ Gonçalo Moniz Institute, Oswaldo Cruz Foundation, Ministry of Health, Salvador, BA, Brazil \\ 'Disease Dynamics Unit, Department of Veterinary Medicine, University of Cambridge, Cambridge, England, United \\ Kingdom
}

\begin{abstract}
Histórico do Artigo:
Recebido em:

$10 / 11 / 2019$

Aceito em:

$18 / 01 / 2020$

Keywords:

Meningitidis;

surveillance;

vaccination strategies; Brazil

\section{ABSTRACT}

Neisseria meningitidis is one of the major etiologic agents of bacterial meningitis and one of the most important causes of invasive bacterial disease worldwide. In Brazil, Invasive meningococcal disease is endemic, predominantly caused by serogroups $\mathrm{C}$ and $\mathrm{B}$ currently. Periods of hyper-endemic have been regularly recorded since the 1920 s. In late 2010 , meningococcal $C$ conjugate vaccine was introduced into the National Immunization Program schedule, with two doses in the first year, at ages 3 and 5 months, and a booster dose at 12 months. This work summarizes available epidemiological data on meningococcal infection in Brazil obtained in the last 10 years from literature review in the PubMed, LILACS and SciELO databases. The incidence of meningococcal C disease has declined as a result of effective vaccination among the age groups targeted for the vaccine. However, no impact was observed in unvaccinated age groups suggesting that there has been little effect on population transmission. Furthermore, we discuss future challenges. It is very important to monitor meningococcal disease in Brazil, identify new strains and to consider the inclusion of a new vaccination strategy.
\end{abstract}

Doença Meningocócica Invasiva no Brasil: uma revisão de literatura

\section{RESUMO}

Neisseria meningitidis é um dos principais agentes etiológicos da meningite bacteriana, uma das causas mais importantes de doença bacteriana invasiva em todo o mundo. No Brasil, a doença meningocócica invasiva é endêmica, atualmente é causada predominantemente pelos sorogrupos $\mathrm{C} e$

Palavras-chave: B. Períodos hiperendêmicos são registrados regularmente desde a década de 1920. No final de 2010, Meningite; vigilância; a vacina conjugada contra meningite $C$ foi introduzida no Programa Nacional de Imunização. As estratégia de vacinação; Brasil crianças recebem duas doses da vacina no primeiro ano de idade, com 3 e 5 meses, e uma dose de reforço aos 12 meses. Este trabalho resume os dados epidemiológicos disponíveis sobre a infecção meningocócica no Brasil, obtidos nos últimos 10 anos através de uma revisão de literatura nos bancos de dados PubMed, LILACS e SciELO. Com a vacinação a incidência da doença meningocócica C diminuiu entre as faixas etárias alvo da vacina. No entanto, nenhum impacto foi observado nas faixas etárias não vacinadas, sugerindo que houve pouco efeito na transmissão da doença na população. Além disso, discutimos desafios futuros. É muito importante monitorar a meningite no Brasil, identificar novas cepas circulantes e considerar a inclusão de novas estratégias vacinais.

\section{Introduction}

Invasive meningococcal disease (IMD), caused by Neisseria meningitidis ( $N$. meningitidis), is an important public health problem. In 2016, the Institute for Health Metrics and Evaluation (IHME) Global Burden of Disease estimated that there were 127 000 deaths and 1.6 million cases of meningococcal disease globally. However, due to inadequate surveillance programs in many parts of the world, IMD is likely to be underreported (1).

In higher income countries, the incidence of IMD tends to be greatest among infants, with a second peak in adolescents and young adults. N. meningitidis is the main etiological agent

\footnotetext{
*Corresponding author: marcellemsilveira@gmail.com (Silveira M.M.)
} 
of meningitis in children above the age of 3 months and in young adults in Brazil (2). The most common clinical manifestations of meningococcal infection are meningitis, septicaemia and less commonly, pneumonia. IMD is associated with high case fatality, of around $10 \%$. Further, IMD can result in significant sequelae, including deafness, skin scarring, chronic pain, neurologic deficiency and amputation (3).

$N$. meningitidis is a Gram-negative, encapsulated, diplococcus and the polysaccharide capsule is used to define 12 serogroups. However, the majority of invasive meningococcal infections are caused by serogroups A, B, C, W, Y, and X are transmitted person-toperson through close contact with infected or colonized individuals (4). In 2010, Brazil introduced the meningococcal $\mathrm{C}$ conjugate vaccine (MCC), which provided protection against serogroup $\mathrm{C}$, into its routine immunization program, with doses scheduled at three and five months of age, plus a booster at 12-15 months of age (5).

\section{Methods}

In this study we searched the literature using Medline (via PubMed), LILACS and SciELO for "Meningococcal disease", or "Invasive Meningococcal disease", or "Neisseria meningitidis", or "carriage" and "Brazil". Studies published in the last 10 years and containing information on IMD in Brazil were included. Abstracts, case reports, letters to the editor, studies with only immunological outcomes, and those reporting results associated with other etiologies of meningitis were excluded (Figure 1). As the final step, key findings from the included publications were synthesized.

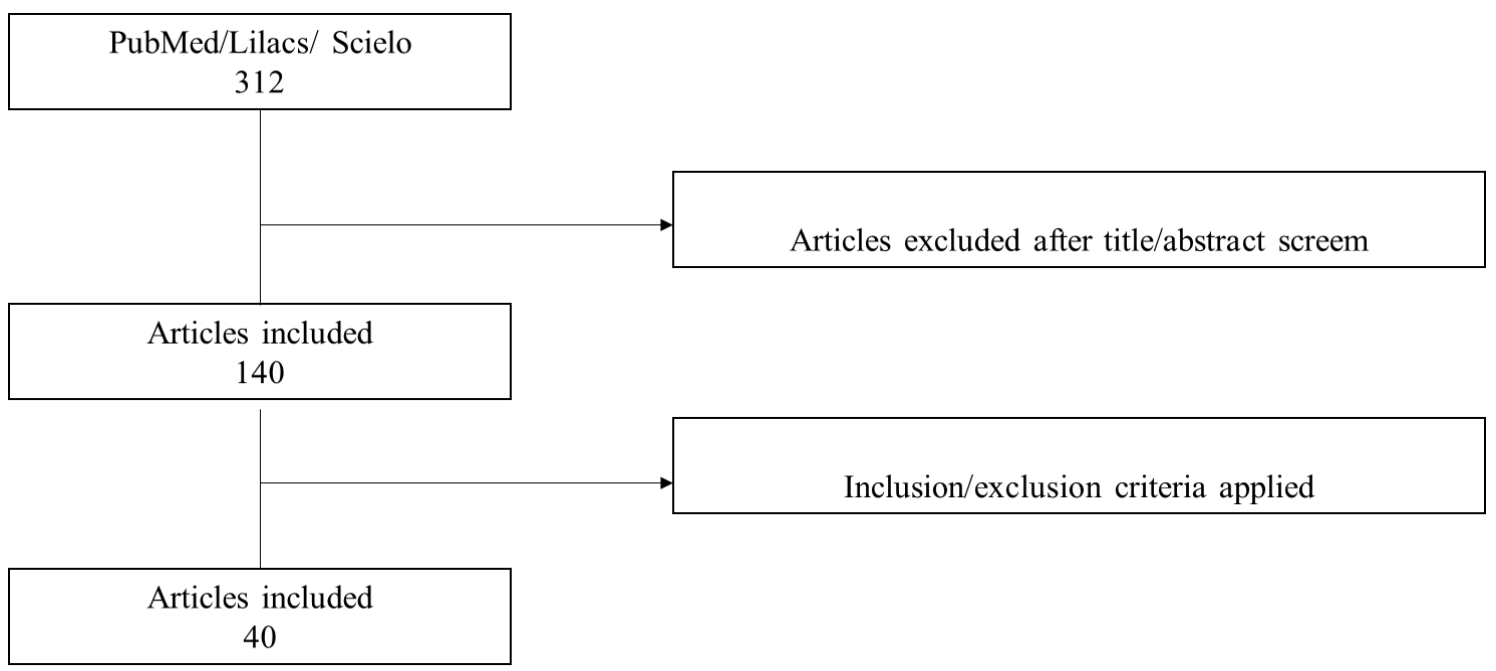

Figure 1 - Selection of studies on invasive meningococcal disease for systematic review

\section{Results and discussion}

\subsection{Epidemiology of IMD in Brazil}

Generally, meningococcal disease is endemic in Brazil, with hyper-endemic periods of increased incidence. In Brazil during the 1920s and 1940s N. meningitidis serogroup A (NmA) caused several epidemics, with an annual incidence of 12-25 per 100000 population (6). Since the 1970s, Brazil experienced three clonal outbreaks of serogroup C disease, caused by C:2a:P1.5,2:ST-11 (cc11), C:2b:P1.3:ST-8 (cc8) and, most recently, since 1989 by C:23:P1.14-6: ST-103 (cc103) (5, 7). However, during the 1980s and 1990s, N. meningitidis serogroup B (NmB) spread throughout Brazil until it became more 
common than serogroup C, with a peak in 1996 of 7.8 cases per 100000 population. Between 1990 and 2001, the annual incidence rate was approximately 1-3 cases per 100 000 population (7). From 1996 to 2002, almost 80\% of reported IMD cases in northern and north-eastern Brazil were caused by serogroup B, and strain B:4:P1.15,19:ST-32 (cc32) predominated throughout the country $(8,9)$.

Another significant shift from $\mathrm{NmB}$ to $\mathrm{NmC}$ was observed from 2002 onwards; a substantial increase in the proportion of cases attributed to serogroup $\mathrm{C}$, associated with appearance of a serogroup C strain belonging to a hypervirulent lineage (ST-103) was recorded and $\mathrm{NmC}$ became the most frequent cause of IMD in Brazil. Serogroup C became predominant in the following regions: Southeast, since 2002-2003; Midwest, since 2005-2006; Northeast, since 2007-2008; Northern, since 2008-2009; and more recently, Southern since 2012 (please see figure 2) (10). In Brazil, the increasing number of cases caused by $\mathrm{NmC}$ prompted the introduction of routine $\mathrm{MCC}$ vaccination in November 2010 (11).

Moreover, there are an increasing number of cases caused by serogroup W (ST-11 complex) (12). According to Abad and colleagues, Brazil was the first country in Latin America to report outbreaks caused by ST-11 serogroup W (13). In recent years there have been virtually no case reports of IMD caused by serogroup A in Brazil (5).
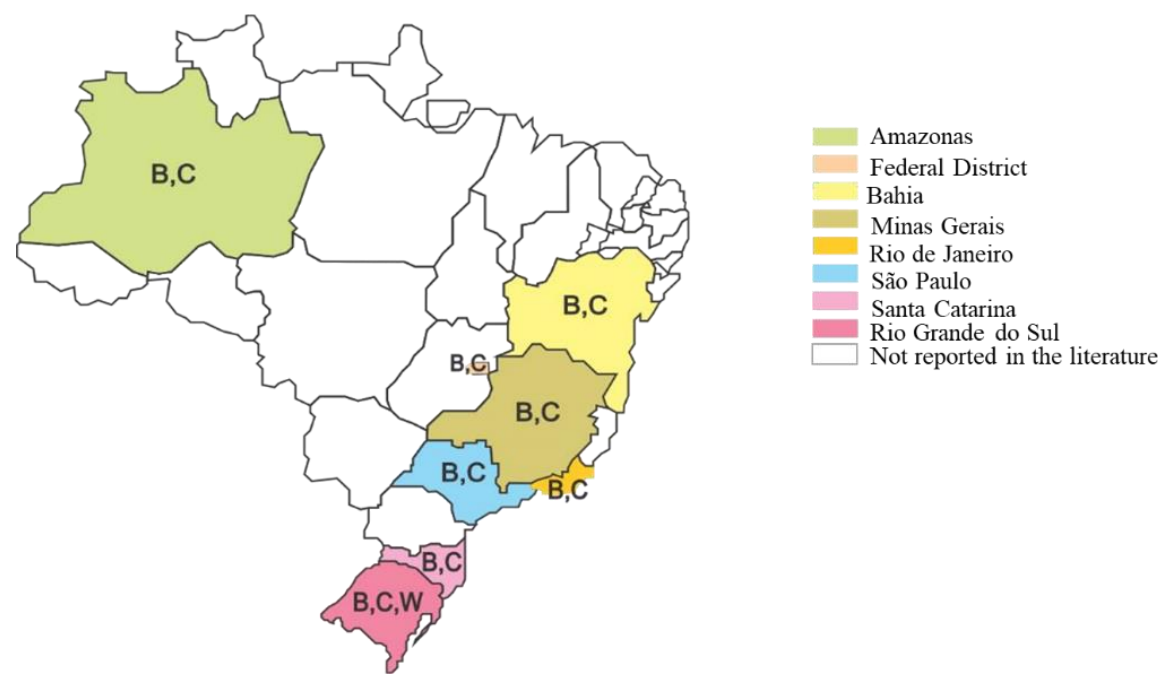

Figure 2 - Map of Brazil, showing the current distribution of major meningococcal serogroups. See text for details.

\subsection{Clinical characteristics}

$N$. meningitidis causes severe and life-threatening invasive disease, such as meningitis and meningococcal sepsis (meningococcemia). In addition, meningococcal infection has a rapid and severe clinical progression over 8 hours, and in some cases results in death within 12-24 hours of onset of symptoms $(1,14)$.

The colonization of the nasopharynx is typically asymptomatic, however, $N$. meningitidis can translocate from nasopharynx to the blood stream, resulting in disease. In previous studies in Brazil, it has been found that in the first 4-6 hours of disease onset, non-specific manifestations mimic the symptoms of common viral infections (15). The median time from symptom onset to hospitalization was one day (ranging from less than $24 \mathrm{~h}$ to five days) and median time from symptom onset to the outcome (discharge/death) 
was 10 days, ranging from less than $24 \mathrm{~h}$ to 123 days (16). Additionally, the overall case fatality rate was $33 \%$, with $50 \%$ of these deaths occurring within 48 hours of hospitalization (17). Similarly, non-specific symptoms in the first 4-6 h has also been reported in England, Wales, and Northern Ireland and mean hospital length of stay was 11 days in Spain (18).

Different studies have detected that clinical symptoms more frequently observed in confirmed cases of IMD in Brazil were fever, vomiting, headache, petechiae, haemorrhagic rash, irritability somnolence and mental confusion, while the least frequent were Kernig's sign, seizures, coma, diarrhoea, abdominal pain, convulsions, sore throat, and myalgia $(19,20)$. Furthermore, among patients <1 year of age an important and frequent symptom was a bulging fontanelle (20). Nascimento and colleagues found that stiff neck was observed in $64.9 \%$ of cases in Minas Gerais, whereas, ISER and colleagues reported that only $5 \%$ of cases presented nuchal rigidity in a study performed in Goias State $(19,20)$.

\subsection{Diagnosis}

The criteria for clinical diagnosis are: fever, stiff neck, severe headache, vomiting, signs of meningeal irritation, seizures, purpuric rash and/or petechiae. In children aged less than 1 year old, IMD should be suspected when fever is accompanied by bulging fontanel (21). Cases are confirmed by the isolation of $N$. meningitidis or by the detection of bacterial DNA by multiplex real-time PCR (RT-PCR) from blood, cerebrospinal fluid (CSF) or skin lesions (21).

In many developing countries, surveillance for bacterial meningitis is limited to the use of bacterial isolation. However, the administration of antibiotics before collection of the CSF, prolonged transport times that compromised sample integrity and the lack of microbiology resources resulted in failure to isolate meningococci (22-24).

PCR techniques have improved the diagnosis of IMD and even when the meningococci were nonviable due to antibiotic treatment, PCR could still detect $N$. meningitidis DNA (25). In Brazil, access to molecular diagnostics is available in sentinel sites in the state of São Paulo and the introduction of RT-PCR for $N$. meningitidis improved the yield for detection in $85 \%$ compared to culture-based methods. Moreover, the sensitivity of RTPCR in cerebrospinal fluid (CSF) was $100 \%$ and specificity ranged from $98.9 \%$ to $100 \%$ was reported (24). The incorporation of molecular diagnostic techniques, like PCR/RTPCR, into routine surveillance and the expanded use of Gram staining, rapid diagnostic tests and culture isolation in Latin America was proposed by Global Meningococcal Initiative (GMI), with the aim to obtain more insight into IMD.

\subsection{Meningococcal carriage}

Acquisition of meningococci in the upper respiratory tract can be transient, can result in meningococcal carriage, or can result in IMD. Carriage plays an important role in the transmission and spread of meningococcal infection (26). For most people, carriage is an immunizing process that results in the production of protective antibodies (27). Nasopharyngeal carriers can transmit meningococci through direct contact with upper respiratory tract secretions and aerosolized droplet nuclei (28).

While the incidence of IMD is highest in infants, the asymptomatic carriage of meningococci in high-income countries is highest among adolescents (29). The relation between disease incidence and carriage prevalence in a population is unclear, but age is one of the most important factors related to carriage rates. The high carriage prevalence 
observed in teenagers in the United Kingdom has been linked to social behaviour such as cigarette smoking, passive exposure to smoke, kissing, overcrowding and socialising in bars and clubs $(30,31)$.

Published data on meningococci carriage in Brazil are limited (Table 1) although studies conducted in the post-MCC vaccination period reported that serogroup $\mathrm{C}$ was predominant, followed by serogroup B. Moreover, the highest carriage prevalence was observed in adolescents aged 10-19 years old $(32,33)$. The carriage prevalence of $N$. meningitidis was $4.9 \%$ among adolescents from Salvador, Bahia, after the mass MCC vaccination campaign. This low rate was potentially influenced by the low prevalence of $\mathrm{NmC}$ during the post-vaccination period in Salvador, as the vaccination campaigns targeted adolescents and young adults. In addition, the campaign may have prevented transmission and colonization of the organism in non-vaccinated individuals through the effect of herd immunity (34). An analysis of risk factors for $N$. meningitidis carriage found that a low level of education (i.e., not completing secondary education) of the parents was associated with increased risk of carriage, probably reflecting socioeconomic conditions (32). Further, factors associated with carriage included having only one, shared bedroom in the household, a mother as the only smoker in the home and going to pubs/parties (3436).

Table 1 - Summarized of N. meningitidis from carriers in Brazil.

\begin{tabular}{ccccc}
\hline State & $\begin{array}{c}\text { Age group targeted for vaccination } \\
\text { campaign }\end{array}$ & $\begin{array}{c}\text { Age of } \\
\text { participants }\end{array}$ & $\begin{array}{c}\text { Prevalence of } \\
\text { carriage }\end{array}$ & References \\
\hline São Paulo & $\leq 1 \mathrm{Y}$ & $18-39$ & $104 / 483(21.5 \%)$ & $(32)$ \\
São Paulo & $\leq 1 \mathrm{Y}$ & $1-24$ & $87 / 967(9 \%)$ & $(33)$ \\
São Paulo & $\leq 1 \mathrm{Y}$ & $11-19$ & $120 / 1,208(9.9 \%)$ & $(35)$ \\
Bahia & $<5 \mathrm{Y}$ and 10-24 Y & $11-19$ & $59 / 1,200(4.9 \%)$ & $(34,37)$ \\
\hline
\end{tabular}

Y: years old.

\subsection{Vaccines}

Since 2005, health technology assessments and economic evaluation studies have been requested for evaluating the introduction of new vaccines into the National Immunization Programme (NIP) (38). Brazil was the first country in Latin America to introduce MCC vaccine in NIP. Routine infant immunization with the MCC vaccine began in Brazil in November 2010, with doses scheduled at three and five months of age, plus a booster at 12-15 months of age. The 3- and 5-month visit schedule was chosen because many vaccines are already given at 2 and 4 months. Toddlers aged between 12-23 months of age received a single dose of the vaccine, without a 'catch-up' campaign in older age groups $(1,39)$. The introduction of the MCC vaccine into the NIP provided an immediate reduction in the incidence of IMD in children aged $<2$ years, the age group targeted for vaccination (40).

The implementation of the MCC vaccine in NIP was done through a partnership between a pharmaceutical company (Novartis vaccines) and a Brazilian public-run vaccine manufacturer (Fundação Ezequiel Dias). All vaccines that are part of the NIP in Brazil are fully funded by the government. Technology transfer from pharmaceutical companies to local vaccine manufacturers in Brazil has resulted in lower prices and increased vaccine supply (39).

The Bexsero vaccine was licensed in Brazil in 2015. Although serogroup B is the second more prevalent in Brazil we showed recently that a vaccination program with Bexsero 
against MenB disease is unlikely to be cost-effective in part, due to high program cost driven by the cost of the Bexsero vaccine (41).

\subsection{Future Challenges}

There was a hyper-endemic period between 1995 and 2000 associated with serogroup W, and this group became endemic again after 2000 in Southern Brazil (42). An unexpected increase in the incidence of $\mathrm{NmW}$ was noticed in different countries in Latin America (13). In Chile, was reported a large increase in the number of cases and in the mortality rate associated with ST11/ET37 CC strains. However, a continuous diversification of the W ST11/ET37 CC with new variants has been associated with clinical cases $(13,43)$. In addition, a meningococcal vaccination program was implemented in Chile with tetravalent (A, C, Y and $\mathrm{W}$ ) conjugate vaccine (21). It is very important to monitor in Brazil the evolution of $\mathrm{NmW}$, identify new strains and to consider the inclusion of this serogroup in any vaccination strategy, particularly in the Southern region.

In relation to serogroup $C$, the MCC vaccine can prevent IMD by direct effects in vaccinated individuals and by indirect effects that benefit unvaccinated individuals, by herd protection. Herd protection arises from meningococcal vaccines, when they prevent acquisition of carriage, which interrupts transmission in the population (34). The success of the MCC vaccination program in reducing disease in the United Kingdom and other European countries was attributed to the combined efficacy of the vaccine by direct and indirect effects $(32,44)$.

In Brazil vaccination programs have successfully reduced, its incidence in those children targeted for vaccination. However, no early impact was observed in other age groups, probably reflecting the lack of a catch-up program including adolescents (40). Additionally, the results of a study performed in Campinas, Brazil, that evaluated the carriage prevalence of $N$. meningitidis among adolescent students between 11-19 years old found that the carriage rate was $9.9 \%$, with an unusually high carriage prevalence for serogroup $\mathrm{C}$ (35). The results of these studies reinforce the importance of considering the catch-up campaign for young people up to the age of 18 years in the NIP to achieve indirect protection. Optimizing strategies for $\mathrm{MenC}$ vaccination to achieve maximum protection in Brazil is strongly recommended.

$N$. meningitidis is still susceptible to most antibiotics that are used for treatment and prophylaxis of IMD, however, the incidence of strains with resistance to antibiotics (as indicated by increased minimum inhibitory concentrations [MIC]) is increasing worldwide (45). Mutations in penA gene are involved with reduced susceptibility to penicillin. Non-susceptibility (or resistance) to penicillin arises from modifications in bacterial penicillin-binding proteins (PBPs), enzymes that are involved in peptidoglycan biosynthesis, that bind to penicillin and other beta-lactam antibiotics.

Alterations in the PBP2 protein encoded by the penA gene led to modifications of the bacteria's peptidoglycan structure, as well as a 10-fold reduction in its affinity for penicillin $(45,46)$. It is also important to consider that strains with reduced susceptibility to penicillin, first-line drug for treating meningococcal infection, have been reported in Brazil and can be represents an additional public health threat (46).

\section{Conflict of interest}

C.T. reports receiving consulting payments from GSK (2013) and an honorarium from Sanofi-Pasteur (2015). 


\section{Financial support}

This work is supported by Brazilian CAPES/PDSE (M.M.S., grant number 88881.136034/2017-01).

\section{References}

1. Borrow R, Alarcon P, Carlos J, Caugant DA, Christensen H, Debbag R, et al. The Global Meningococcal Initiative: global epidemiology, the impact of vaccines on meningococcal disease and the importance of herd protection. Expert Rev Vaccines 2017; 16(4): 313-28.

2. Strelow VL, Miranda EJ, Kolbe KR, Framil JV, Oliveira AP, Vidal JE. Meningococcal meningitis: clinical and laboratorial characteristics, fatality rate and variables associated with in-hospital mortality. Arquivos de neuro-psiquiatria 2016; 74(11): 875-80.

3. Olbrich KJ, Muller D, Schumacher S, Beck E, Meszaros K, Koerber F. Systematic Review of Invasive Meningococcal Disease: Sequelae and Quality of Life Impact on Patients and Their Caregivers. Infectious diseases and therapy 2018; 7(4): 421-438.

4. Booy R, Gentile A, Nissen M, Whelan J, Abitbol V. Recent changes in the epidemiology of Neisseria meningitidis serogroup $\mathrm{W}$ across the world, current vaccination policy choices and possible future strategies. Hum Vaccin Immunother 2019; 15(2): 470-480.

5. Safadi MA, Bettinger JA, Maturana GM, Enwere G, Borrow R. Global Meningococcal I. Evolving meningococcal immunization strategies. Expert review of vaccines 2015; 14(4): 505-17.

6. Harrison LH, Trotter CL, Ramsay ME. Global epidemiology of meningococcal disease. Vaccine 2009; 27 Suppl 2:B51-63.

7. Lemos AP, Brandao AP, Gorla MC, Paiva MV, Simonsen V, Melles CE. Phenotypic characterization of Neisseria meningitidis strains isolated from invasive disease in Brazil from 1990 to 2001. Journal of medical microbiology 2006; 55(Pt 6): 751-7.

8. de Filippis I, de Lemos AP, Hostetler JB, Wollenberg K, Sacchi CT, Dunning Hotopp JC, et al. Molecular epidemiology of Neisseria meningitidis serogroup B in Brazil. PloS one 2012; 7(3): e33016.

9. Sridhar S, Greenwood B, Head C, Plotkin SA, Safadi MA, Saha S, et al. Global incidence of serogroup B invasive meningococcal disease: a systematic review. The Lancet Infectious diseases 2015; 15(11): 1334-46.

10. Moraes C, Moraes JC, Silva GD, Duarte EC. Evaluation of the impact of serogroup C meningococcal disease vaccination program in Brazil and its regions: a population-based study, 2001-2013. Memorias do Instituto Oswaldo Cruz. 2017; 112(4): 237-46.

11. Andrade AL, Minamisava R, Tomich LM, Lemos AP, Gorla MC, de Cunto Brandileone MC, et al. Impact of meningococcal $C$ conjugate vaccination four years after introduction of routine childhood immunization in Brazil. Vaccine 2017; 35(16): 2025-33.

12. Constenla D, Carvalho A, Alvis Guzman N. Economic Impact of Meningococcal Outbreaks in Brazil and Colombia. Open forum infectious diseases. 2015; 2(4):ofv167.

13. Abad R, Lopez EL, Debbag R, Vazquez JA. Serogroup W meningococcal disease: global spread and current affect on the Southern Cone in Latin America. Epidemiology and infection 2014; 142(12): 2461-70.

14. Demissie DE, Kaplan SL, Romero JR, Leake JA, Barson WJ, Halasa NB, et al. Altered neutrophil counts at diagnosis of invasive meningococcal infection in children. The Pediatric infectious disease journal 2013; 32(10): 1070-2.

15. Strelow VL, Vidal JE. Invasive meningococcal disease. Arquivos de neuro-psiquiatria 2013; 71(9B): 653-8.

16. Tauil Mde C, Carvalho CS, Vieira AC, Waldman EA. Meningococcal disease before and after the introduction of meningococcal serogroup C conjugate vaccine. Federal District, Brazil. The Brazilian journal of infectious diseases : an official publication of the Brazilian Society of Infectious Diseases 2014; 18(4): 379-86.

17. Bryan JP, de Silva HR, Tavares A, Rocha H, Scheld WM. Etiology and mortality of bacterial meningitis in northeastern Brazil. Reviews of infectious diseases 1990; 12(1): 128-35. 
18. Thompson MJ, Ninis N, Perera R, Mayon-White R, Phillips C, Bailey L, et al. Clinical recognition of meningococcal disease in children and adolescents. Lancet 2006; 367(9508): 397-403.

19. Iser BP, Lima HC, de Moraes C, de Almeida RP, Watanabe LT, Alves SL, et al. Outbreak of Neisseria meningitidis $\mathrm{C}$ in workers at a large food-processing plant in Brazil: challenges of controlling disease spread to the larger community. Epidemiology and infection 2012; 140(5): 906-15.

20. Nascimento KA, Miranzi Sde S, Scatena LM. Epidemiological profile of meningococcal disease in the State of Minas Gerais and in the Central, North, and Triangulo Mineiro regions, Brazil, during 20002009. Revista da Sociedade Brasileira de Medicina Tropical 2012; 45(3): 334-9.

21. Safadi MA, O'Ryan M, Valenzuela Bravo MT, Brandileone MC, Gorla MC, de Lemos AP, et al. The current situation of meningococcal disease in Latin America and updated Global Meningococcal Initiative (GMI) recommendations. Vaccine 2015; 33(48): 6529-36.

22. Sacchi CT, Zanella RC, Caugant DA, Frasch CE, Hidalgo NT, Milagres LG, et al. Emergence of a new clone of serogroup C Neisseria meningitidis in Sao Paulo, Brazil. Journal of clinical microbiology 1992; 30(5): 1282-6.

23. Corless CE, Guiver M, Borrow R, Edwards-Jones V, Fox AJ, Kaczmarski EB. Simultaneous detection of Neisseria meningitidis, Haemophilus influenzae, and Streptococcus pneumoniae in suspected cases of meningitis and septicemia using real-time PCR. Journal of clinical microbiology 2001; 39(4): 15538.

24. Sacchi CT, Fukasawa LO, Goncalves MG, Salgado MM, Shutt KA, Carvalhanas TR, et al. Incorporation of real-time PCR into routine public health surveillance of culture negative bacterial meningitis in Sao Paulo, Brazil. PloS one 2011; 6(6):e20675.

25. Drew RJ, C OM, Gavin PJ, N OS, Butler KM, Cafferkey M. The impact of meningococcal polymerase chain reaction testing on laboratory confirmation of invasive meningococcal disease. The Pediatric infectious disease journal 2012; 31(3): 316-8.

26. Stefanelli P, Rezza G. Impact of vaccination on meningococcal epidemiology. Hum Vaccin Immunother 2016; 12(4): 1051-5.

27. Baker CJ. Prevention of Meningococcal Infection in the United States: Current Recommendations and Future Considerations. The Journal of adolescent health : official publication of the Society for Adolescent Medicine 2016; 59(2 Suppl): S29-37.

28. Kellerman SE, McCombs K, Ray M, Baughman W, Reeves MW, Popovic T, et al. Genotype-specific carriage of Neisseria meningitidis in Georgia counties with hyper- and hyposporadic rates of meningococcal disease. The Journal of infectious diseases. 2002; 186(1): 40-8.

29. Watson PS, Turner DP. Clinical experience with the meningococcal B vaccine, Bexsero((R)): Prospects for reducing the burden of meningococcal serogroup B disease. Vaccine 2016; 34(7): 875-80.

30. Read RC, Baxter D, Chadwick DR, Faust SN, Finn A, Gordon SB, et al. Effect of a quadrivalent meningococcal ACWY glycoconjugate or a serogroup B meningococcal vaccine on meningococcal carriage: an observer-blind, phase 3 randomised clinical trial. Lancet 2014; 384(9960): 2123-31.

31. Christensen H, May M, Bowen L, Hickman M, Trotter CL. Meningococcal carriage by age: a systematic review and meta-analysis. The Lancet Infectious diseases 2010; 10(12): 853-61.

32. Safadi MA, Carvalhanas TR, Paula de Lemos A, Gorla MC, Salgado M, Fukasawa LO, et al. Carriage rate and effects of vaccination after outbreaks of serogroup $\mathrm{C}$ meningococcal disease, Brazil, 2010. Emerging infectious diseases 2014; 20(5): 806-11.

33. Weckx LY, Puccini RF, Machado A, Goncalves MG, Tuboi S, Barros E, et al. A cross-sectional study assessing the pharyngeal carriage of Neisseria meningitidis in subjects aged 1-24 years in the city of Embu das Artes, Sao Paulo, Brazil. The Brazilian journal of infectious diseases : an official publication of the Brazilian Society of Infectious Diseases 2017; 21(6):587-595.

34. Nunes AM, Ribeiro GS, Ferreira IE, Moura AR, Felzemburgh RD, de Lemos AP, et al. Meningococcal Carriage among Adolescents after Mass Meningococcal C Conjugate Vaccination Campaigns in Salvador, Brazil. PloS one 2016; 11(11): e0166475.

35. Cassio de Moraes J, Kemp B, de Lemos AP, Outeiro Gorla MC, Lemes Marques EG, Ferreira Mdo C, et al. Prevalence, Risk Factors and Molecular Characteristics of Meningococcal Carriage Among Brazilian Adolescents. The Pediatric infectious disease journal 2015; 34(11): 1197-202.

36. Coch Gioia CA, Silva de Lemos AP, Outeiro Gorla MC, Mendoza-Sassi RA, Ballester T, Von Groll A, et al. Detection of Neisseria meningitidis in asymptomatic carriers in a university hospital from 
Brazil. Revista Argentina de microbiologia 2015; 47(4):322-7.

37. Moura A, Kretz CB, Ferreira IE, Nunes A, de Moraes JC, Reis MG, et al. Molecular characterization of Neisseria meningitidis isolates recovered from 11-19-year-old meningococcal carriers in Salvador, Brazil. PloS one 2017; 12(9): e0185038.

38. de Soarez PC, Sartori AM, Freitas AC, Nishikawa AM, Novaes HM. Cost-Effectiveness Analysis of Universal Vaccination of Adults Aged 60 Years with 23-Valent Pneumococcal Polysaccharide Vaccine versus Current Practice in Brazil. PloS one 2015; 10(6): e0130217.

39. Ruttimann RW, Gentile A, Parra MM, Saez-Llorens X, Safadi MA, Santolaya ME. A consensus statement: meningococcal disease among infants, children and adolescents in Latin America. The Pediatric infectious disease journal 2014; 33(3): 284-90.

40. Safadi MA, Berezin EN, Arlant LH. Meningococcal Disease: Epidemiology and Early Effects of Immunization Programs. Journal of the Pediatric Infectious Diseases Society 2014; 3(2): 91-3.

41. Moura Silveira M, McBride AJA, Trotter CL. Health impact and cost-effectiveness of introducing the vaccine (Bexsero) against MenB disease into the Brazilian immunization programme. Vaccine 2019; 37(45): 6783-6.

42. Weidlich L, Baethgen LF, Mayer LW, Moraes C, Klein CC, Nunes LS, et al. High prevalence of Neisseria meningitidis hypervirulent lineages and emergence of W135:P1.5,2:ST-11 clone in Southern Brazil. The Journal of infection 2008; 57(4): 324-31.

43. Araya P, Fernandez J, Del Canto F, Seoane M, Ibarz-Pavon AB, Barra G, et al. Neisseria meningitidis ST-11 clonal complex, Chile 2012. Emerging infectious diseases 2015; 21(2): 339-41.

44. Trotter CL, Maiden MC. Meningococcal vaccines and herd immunity: lessons learned from serogroup C conjugate vaccination programs. Expert review of vaccines 2009; 8(7): 851-61.

45. Acevedo R, Bai X, Borrow R, Caugant DA, Carlos J, Ceyhan M, et al. The Global Meningococcal Initiative meeting on prevention of meningococcal disease worldwide: Epidemiology, surveillance, hypervirulent strains, antibiotic resistance and high-risk populations. Expert review of vaccines 2019; 18(1): 15-30.

46. Fonseca EL, Marin MA, Freitas FS, Vitorio BSA, de Araujo FMG, Camargo DRA, et al. The invasive MenC cc103 lineage with penicillin reduced susceptibility persisting in Brazil. International journal of medical microbiology : IJMM. 2017; 307(6): 287-90. 